\title{
OXFORD UNIVERSITY.
}

$A_{T}$ Oxford University two degrees in medicine can be obtained, the M.B. and the M.D.; similarly in surgery there are two degrees, the B.Ch. and the M.Ch. No candidate is eligible for any of these degrees unless he is a graduate in Arts, that is to say, either an M.A. or a B.A.; i. which branch of the Arts that degree has been obtained is a matter of little moment. The usual course of the medical student, who has passed Responsions, is to come up to Oxford and work at the Preliminary Science examinations, which are likely to take him two years or thereabouts, and then to spend a further two years in study for the Final Honour School of Physiology, in which he takes his degree of B.A. He next has to pass examinations in Human Anatomy, and Materia Medica with Pharmacy, after which he proceeds to some town in which the opportunities for clinical study are greater than they are at Oxford, and prepares himself there for his second Professional examination, which comprises the subjects of Medicine, Surgery, Midwifery, Pathology, Forensic Medicine, and Hygiene. When this has been passed, the candidate may supplicate for and obtain the degree of M.B., B.Ch.

The degree of M.D. is granted to Bachelors of Medicine of the University who have entered their thirty-ninth term -it should be remembered that there are four terms in the official year-who have presented a dissertation on some medical subject that is approved by the Professors of the Faculty and Examiners for the degree of Bachelor of Medicine for the time being whose subjects are dealt with in it. The degree of M.Ch. is granted to Bachelors of Surgery of the University who have entered their twenty-seventh term and satisfied some other requirements; the examination for this degree is held annually in June.

\section{THE LONDON UNIVERSITY COURSE.}

THE University confers the degrees of Bachelor of Medicine and Bachelor of Surgery (M.B., B.S.), Doctor of Medicine (M.D.) and Master of Surgery (M.S.).

The student who desires to take the degree of M.B. of the London University has to pass the University Matriculation Examination, held thrice yearly in January, September, and June. The matriculation is accepted as a preliminary examination for graduation or qualification in medicine, provided the candidate has taken Latin as one of the optional subjects, and formerly no other examination exempted from the matriculation so far as degrees of the University were concerned. Recently, however, the Senate has seen fit to rule that several other examinations may be accepted instead of the usual matriculation.

After matriculating the student must attach himself to one or other of the various medical schools, and devote himself during his first year to mastering the subjectschemistry, biology, and physics-required for his preliminary scientific or first professional examination. It will take him a full year to work up these subjects.

The student is at present admitted to the Intermediate examination, the subjects of which consist of anatomy, physiology, and pharmacology, two years after having passed Part I. of the Preliminary. Time spent in working at the subjects of anatomy and physiology is not recognised by the University until the student has passed the Preliminary. His second and third years are thus spent in work in the dissecting room and physiological laboratory.

Having passed his "Inter.," the student begins clinical work. Two years of clinical study were formerly required, but now three years wiil be necessary, while two and a half years will be the minimum period required for the preliminary subjects. Thus the full course will in future occupy at least five and a half years from the time of matriculation.

The final is by no means a stiff examination; compared with the Preliminary examination it is even an easy one. Special attention must be paid to a few subjects. Thus the student will do well to keep himself acquainted with pathology and morbid anatomy; midwifery and forensic medicine, also, are subjects in which many candidates fail. The last examination is written, oral, and practical. The candidate is required to examine and report on selected cases, to do practical bacteriological work, and to be acquainted with the essentials of operative surgery, though actual operations on the dead subject are not demanded.

\section{HIGHER DIPLOMAS.}

The Royal College of Physicians of London grants its membership after examination to graduates in medicine of recognised Universities, or to licentiates of the College, being above the age of twenty-five years, who do not engage in trade, do not dispense medicine, and who do not practise in partnership. The examination, which is held in January, April, July, and October, is partly written and partly oral. The fee for the membership is $£ 42$, but if the candidate is a licentiate the fee is the difference between what he has already paid and $£ 42$. In either case $£ 66$ s. is paid before examination. The fellowship is elective.

The Royal College of Physicians of Edinburgh admits to its membership licentiates of the College, or of a British or Irish College of Physicians, or graduates in medicine of a British or Irish University over twenty-four years of age after examination in medicine and therapeutics and one or more of the following subjects selected by the candidate: (1) One or more departments of medicine specially professed, (2) psychological medicine, (3) general pathology and morbid anatomy, (4) medical jurisprudence, (5) public health, (6) midwifery, (7) diseases of women, (8) diseases of children, (9) tropical medicine. The fee

to be paid by a licentiate is twenty guineas, by others thirty-five guineas. A member of three years' standing may be elected a Fellow. The fee is $£ 6418 \mathrm{~s}$.

The Royal College of Surgeons of Edinburgh.-The Fellowship is granted, after examination, to any registered practitioner who is twenty-five years of age and has been in practice for two years. The examinations are written, oral, and practical. The fee is $£ 35$ to those who hold the diploma of licentiate of the College, and $£ 45$ to others (no. stamp duty is payable on the diploma).

The Faculty of Physicians and Surgeons of Glasgow.Registered practitioners are admitted to the Fellowship by examination and by subsequent election. Four examinations are held annually (January, April, July, October). Fourteen days' notice must be given. The fee is $£ 30$ unless the candidate desires to qualify to hold office, when it is $£ 50$. In the case of a licentiate of the faculty, £25 and $£ 15$ respectively.

Royal College of Surgeons in Ireland Fellowship.(1) The examination for the Fellowship is divided into two parts-namely, the Primary and the Final. (2) The subjects of the Primary examination are anatomy (including dissec. 